ENCYCLOPEDDIE Encyclopédie berbère

BERBERE

3 | 1986

3 | Ahaggar - Alī ben Ghaniya

\title{
Aïssi (Aït)
}

C. El Briga

\section{OpenEdition}

Journals

Édition électronique

URL : http://journals.openedition.org/encyclopedieberbere/2380

DOI : 10.4000/encyclopedieberbere.2380

ISSN : 2262-7197

\section{Éditeur}

Peeters Publishers

\section{Édition imprimée}

Date de publication : 1 juillet 1986

Pagination : 381-383

ISBN : 2-85744-260-2

ISSN : 1015-7344

\section{Référence électronique}

C. El Briga, «Aïssi (Aït)», Encyclopédie berbère [En ligne], 3 | 1986, document A127, mis en ligne le 01 septembre 2012, consulté le 12 octobre 2020. URL : http://journals.openedition.org/ encyclopedieberbere/2380; DOI : https://doi.org/10.4000/encyclopedieberbere.2380

Ce document a été généré automatiquement le 12 octobre 2020

(c) Tous droits réservés 


\section{Aïssi (Aït)}

\section{El Briga}

1 «Tribu » de Grande Kabylie qui occupe un terrain montagneux à une douzaine de km de Tizi Ouzou, entre les Aït Douala au nord, les Ait Mahmoud et les Ouadhias au sud. Les Ait Aïssi sont limités à l'est par l'oued qui porte leur nom et qui se trouve être le principal affluent du Sebaou. Leurs principaux villages sont Taguemmount ou Kerrouch et Ighil Bouzrou.

2 Les Aït Aïssi sont réputés pour la qualité des produits de leur artisanat féminin, surtout les tissages et les poteries. Cette réputation sans être surfaite est cependant partagée par beaucoup d'autres groupes kabyles : les Ouadhias et les Aït Khellili pour la poterie, les Aït Hichem et les Ait Mangellat pour les tissages, mais les Aït Aïssi, comme leurs voisins du nord les Aït Douala, ont été parmi les premiers Kabyles à entrer en contact avec l'administration coloniale et très vite leur artisanat fut apprécié à sa juste valeur. Ainsi dès 1852 , le $\mathrm{D}^{\mathrm{r}}$ Verdalle recueillait plusieurs caisses de poteries chez leurs voisins, les Mechtras.

3 Les poteries des Aït Aïssi sont généralement d'une élégante sobriété, tant dans leur ligne marquée, sur les pots et les cruches, par un ressaut au niveau de l'épaulement, que dans le décor caractérisé par ses "fenêtres » blanches, cernées d'un ou plusieurs traits noirs, qui sont découpées dans de larges zones rouges. Celles-ci occupent le haut des vases et descendent en compartiments de part et d'autre des anses qui demeurent blanches. Dans les grands récipients, comme les amphores, la panse reste inornée, en revanche sur les pots et cruches le décor gagne toute la surface, mais c'est là un caractère commun à toute la production kabyle. Dès le troisième tiers du XIX ${ }^{e}$ siècle, les Aït Aïssi, sollicités par des marchands, produisirent une vaisselle de circonstance destinée à une clientèle européenne. 

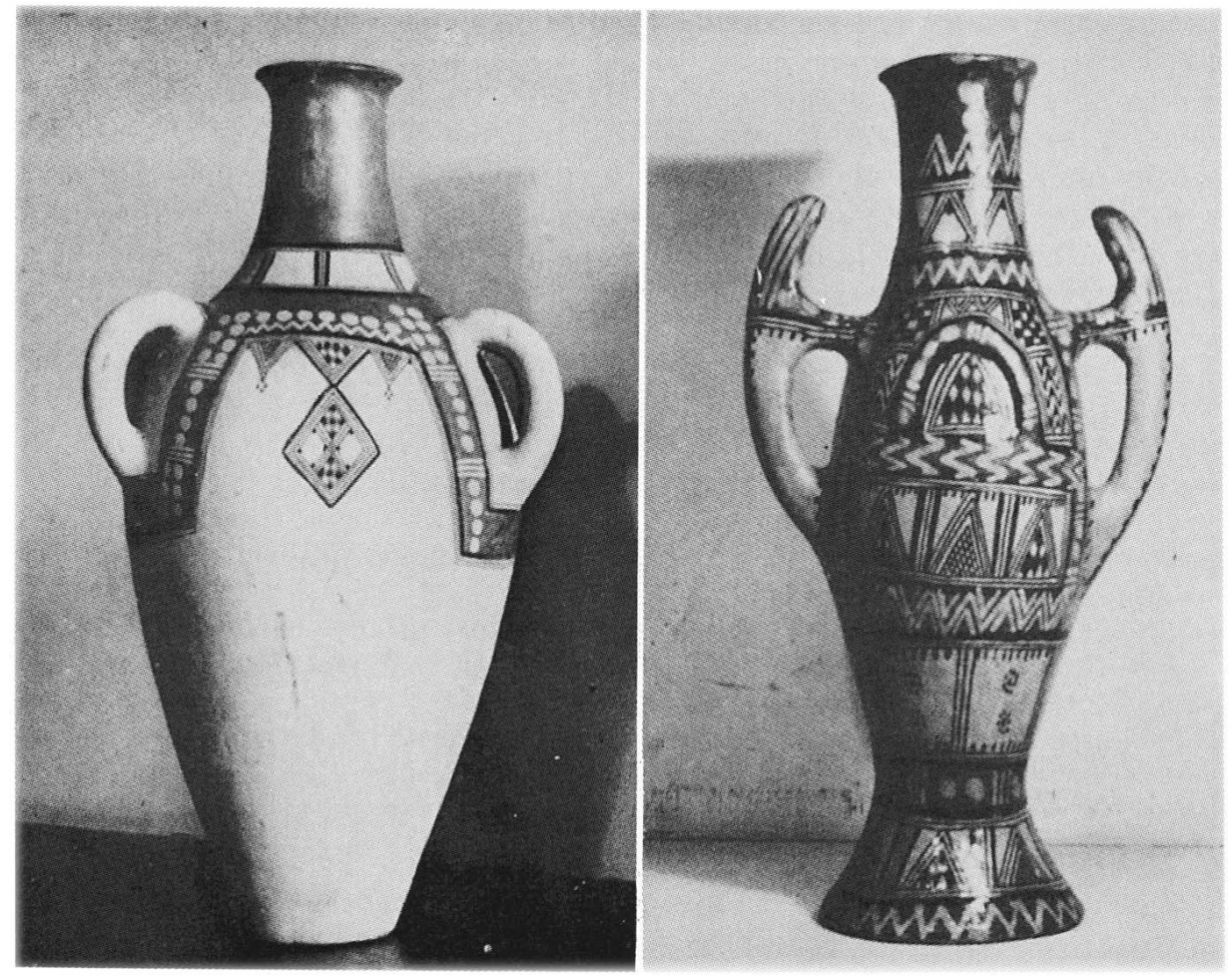

4 Cette fabrication pour étranger se distingue au premier coup d'œil des produits à usage domestique. Les formes sont moins pures et aboutissent même à des monstruosités, telles ces amphores de taille réduite dont le pied élargi en pavillon supporte un corps aminci qui paraît d'autant plus grêle qu'il est muni d'anses démesurées; le décor envahissant occupe toute la surface qui a été passée à la résine (remplacée aujourd'hui par un vernis industriel), alors que ce procédé n'est pas appliqué sur les grandes poteries à usage domestique. Ces amphorettes de cheminée, généralement très mal cuites, ont une existence brève, toutefois elles ont été figurées par A.Van Gennep dans ses Études d'Ethnographie algérienne, et certaines sont conservées, à juste titre, dans les collections du Musée de Préhistoire et d'Ethnographie du Bardo, à Alger.

Les tissages des Aït Aïssi ont fait l'objet d'une étude très précise de P. Ricard (Hespéris, 1925, p. 219-225) à qui nous empruntons les éléments suivants : Les femmes Aït Aïssi se livrent à un genre de tissage orné à poils ras assez différent du tissage traditionnel des autres tribus de la Grande Kabylie. Le genre Aït Aïssi est très reconnaissable. Il ne s'applique, comme ailleurs, qu'au vêtement féminin, c'est-à-dire qu'au grand haik de laine qui fait le tour du corps (ahellāl). La couverture épinglée sur le haik lors des grands froids est également décorée (tamendilt). Ces pièces rectangulaires ne sont ni coupées ni cousues, elles sont maintenues par deux fibules placées à hauteur de la poitrine. La chaîne et la trame sont faites de fils très fins filés par les femmes. P. Ricard indique que sur une pièce de qualité moyenne on ne compte pas moins de 12 à 15 fils de chaîne pour 24 à 30 trames au centimètre. Le passage des trames tantôt en laine écrue, tantôt en laine teintée en bleu, tantôt en coton blanc, donne le décor.

6 Les motifs les plus simples sont des filets de coton blanc. Des bandes de laine bleue sont bordées de zig-zag ou de dents de scie qui sont aussi en coton tranchant sur le fond de laine non teinte. L'intérieur des bandes bleues possède aussi des motifs en chaînettes, 
chevrons, damiers, bâtonnets ou autres petits signes rigoureusement géométriques qui portent chacun un nom imagé (anquīa $b$ urzem: cou de serpent, tit $b$ ufrūh: œil d'oiseau...) Tous ces motifs sont groupés parallèlement en un nombre variable de rayures, il n'y a donc aucune composition verticale. Dans la fabrication traditionnelle telle qu'elle était décrite par P. Ricard en 1925, la pièce une fois tissée ne comptait que de larges bandes bleues, des motifs en coton blanc et des bandes de laine écrue. On procédait alors à un trempage dans un bain rouge grenat qui avait pour résultat de noircir les bandes bleues, de teindre en rouge la laine écrue tandis que les motifs en coton, qui n'avait pas subi de mordançage préalable, redevenaient blancs après un simple rinçage.

\section{BIBLIOGRAPHIE}

BALFET H. Les poteries modelées d'Algérie dans les collections du Musée du Bardo. C.R.A.P.E., Alger Imp. off., 1975.

RICARD P. Tissage berbère des Ait Aïssi (Grande Kabylie). Hespéris, t.V, 1925, p. 219-225.

VAN GENNEP A. Etudes d'Ethnographie algérienne. Paris, Leroux, 1911.

VERDALLE A. Poterie kabyle trouvée dans la tribu des Mechtras (Kabylie indépendante).

L'Illustration, Journal universel, janvier 1852, p.30-36.

\section{INDEX}

Mots-clés : Algérie (partie nord), Artisanat, Tribus 